\title{
Perinatal morbidity and mortality and the impact of neonatal resuscitation day-by-day calamity evidenced by a prospective descriptive study in Guinea-Conakry
}

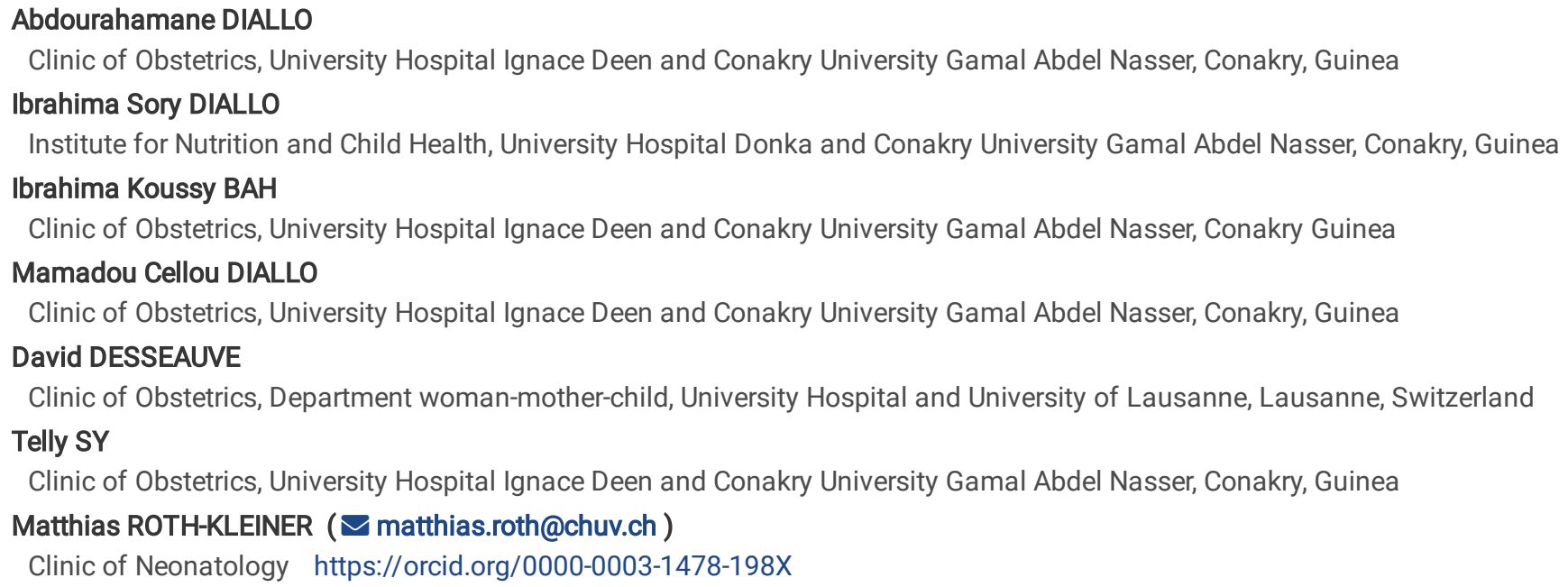

Keywords: Stillbirth, Neonatal resuscitation, Neonatal mortality rate, Perinatal mortality rate, Stillbirth, Chest compression

Posted Date: June 8th, 2020

DOI: https://doi.org/10.21203/rs.3.rs-31617/v1

License: (c) (1) This work is licensed under a Creative Commons Attribution 4.0 International License. Read Full License 


\section{Abstract \\ Background}

Perinatal mortality represents a major health care problem in particular in low and middle-income countries, which account for $97 \%$ of all late fetal and $98 \%$ of all neonatal deaths. Our objectif was to analyse perinatal morbidity and mortality at the largest maternity clinic of Guinea, in sub-Saharan Africa.

\section{Patients \& Methods:}

Prospective observational evaluation of the perinatal morbidity and mortality between May 1 st and June 30 th 2019 at the Clinic of Obstetrics of the University Hospital Ignace Deen in Conakry, Guinea.

\section{Results}

Of the 1189 deliveries, 98 (82\%o) fetus were born dead, $58.1 \%$ of them with signs of maceration. $14.1 \%$ of all infants had low birth weight (< $2500 \mathrm{~g}$ ) and $10.6 \%$ were macrosome (> $4000 \mathrm{~g})$. The rate of preterm infants was $9.3 \%$ and 99 infants (8.3\%) showed signs of post-maturity. At birth, $6.8 \%$ of all live born infants had asphyxia, $10.9 \%$ respiratory distress, $1.9 \%$ infection, $0.3 \%$ malformation, and nine infants died within the first postnatal minutes. Need for any resuscitation manoeuvres showed 304 infants (27.9\%), 68.8\% of them needed bag and mask ventilation and $27.0 \%$ chest compressions. Infants with bad Apgar score at 1 and 5 minutes did improve by 10 minutes thanks to respiratory support, but not due to chest compression. As there is no neonatal unit in the same hospital, 192 infants (17.6\%) had to be transferred across Conakry to the only tertiary neonatal unit. Due to lack of any (para-)medical transport system for newborn infants, mortality of these neonates is very high and adds to the total perinatal mortality of 143.8 deaths/1000 deliveries.

\section{Conclusions}

Late pregnancy control is very poor in Conakry, leading to delayed referral of high-risk pregnancies to the university hospital. This goes along with high rates of stillbirths, post-term and macrosome infants with increased risk for delivery complications like postnatal adaptation problems and asphyxia. Resuscitation algorithm needs to be adapted to the local context. A hospital-based neonatal unit for primary stabilization and a medicalised neonatal transport system within Conakry needs to be implemented to decrease the high mortality rate.

\section{Background}

Stillbirths and neonatal mortality are major health care problems especially in low and middle-income countries (LMIC) where $98 \%$ of all neonatal and $97 \%$ of all late fetal deaths are reported (1-3). Although a lot effort has been made worldwide to decrease under 5 -mortality rate (U5MR) by 50\% between 1990 and 2015, the millennium developmental goal number 4 (MDG 4) fell short to reach the planned 75\% reduction, leading to the Every Newborn action plan $(4,5)$. An important reason for missing the goal is an ongoing high neonatal mortality representing death within the first 28 days after birth. Furthermore, neonatal and U5MR refer to live births and therefore do not include stillbirths. According to the WHO health report $2005,21 \%$ of all death before 5 years of age concern fetal deaths, $21 \%$ occur within the first week of life (early neonatal deaths), $8 \%$ within second and fourth postnatal week (late neonatal deaths), 28\% between postnatal month 2-12 (postneonatal deaths) and $28 \%$ during second to fifth year of age (6). It is estimated that about 2.5 million newborn infants die each year, almost three quarters of them within the first week of life. To focus on late pregnancy and delivery control, as well as early neonatal care, the term of perinatal mortality was defined, as the sum of stillbirths and early neonatal deaths (within the first seven postnatal days) per 1000 deliveries (7). Data about stillbirth rates are in many regions inexistent or underreported. Globally, the number of stillbirths is estimated at about 2.6 million deaths per year, similar to the number of newborn deaths. However, less reduction in stillbirth rates compared to neonatal mortality rates have been observed over the last decades (8). Scarce data are available about stillbirth and perinatal mortality rates from hospitals or urban regions in LMIC (9-11).

Nationwide data are mostly estimates, based on demographic and health inquiries and multiple indicator cluster surveys (MICS). The latest data set for Guinea is the MICS 2018, estimating neonatal mortality rate as 32 per 1000 live births (LB), but no official data about stillbirths exist (12), meaning that no data are available about perinatal mortality. In order to fill this gap of knowledge, we performed a prospective analysis of all birth activities at the largest maternity of the Republic of Guinea. In particular, we focused on postnatal adaptation, neonatal morbidity and perinatal mortality.

\section{Patients \& Methods}


This prospective and descriptive analysis of all deliveries during a two months period (May 1st - June 30th 2019) has been done at the clinic of obstetrics of the National University Hospital Ignace Deen in Conakry. With about 6'000 deliveries per year, it represents by far the largest maternity clinics of all Guinea. All deliveries of dead fetus with BW >1000 g and live born infants were included in the study. Data collection comprised documentation of maternal health during pregnancy and delivery and data of the charts of the newborn infants regarding postnatal adaptation, need for resuscitation, body measurements (BW: birth weight, length, and head circumference), and need and the reason for transfer to the neonatal unit. Gestational age (GA) in weeks was defined as the interval between the first day of last menstruation and birth or the age determined by echography performed before 20 weeks of gestation. Degree of prematurity was defined as extremely preterm (<28 weeks GA), very preterm (GA 28 0/7-31 6/7), moderately preterm (GA 32 0/7-33 6/7) and late preterm infants (GA 34 0/7-36 6/7). Descriptive statistical analysis consisted in calculation of means, standard deviation (SD) and median values with the respective range. We performed a subgroup analysis, focused on newborns with an Apgar < 4 at 1 minute and on newborns with poor prognosis, defined in our study with an Apgar score < 4 at 1 minute and/or Apgar score $<7$ at 5 minutes. In these two subgroups, crude associations between primary resuscitation measures, and an improvement to Apgar score > 7 at 10 minutes were quantified by odds ratios and their $95 \%$ confidence intervals (Cis). Multivariate analysis followed in order to obtain a better estimate of the role of ventilatory support (including airway suctioning and bag and mask ventilation) and cardiac massage to obtain and Apgar > 7 at 10 minutes in the two subgroups. The data was analyzed with Stata (version 16IC; Stata corporation, College station, Texas, USA).

\section{Results}

During the two months study period, 1189 deliveries were registered. From these, 98 were stillbirths (8.2\%), of which 57 (58.1\%) showed macerations as sign of prolonged intrauterine death and $41(41.8 \%)$ were without macerations, commonly defined as a surrogate for intrapartum stillbirths (Table 1). Prematurity rate was $9.3 \%$, and $8.3 \%$ of infants were born post term. Figure 1 shows the distribution of the preterm infants according to the different gestational age groups. Mean birth weight (BW) of all newborns was $2938 \mathrm{~g}(+/-736 \mathrm{~g})$, with $14.1 \%$ being low BW (LBW, < $2500 \mathrm{~g})$ and $10.6 \%$ macrosome infants with a BW of $>4000 \mathrm{~g}$. There was a light female predominance with $624 \mathrm{girls}$ (52.5\%). Of the 1091 live births (LB), only 513 infants (47.0\%) were born by vaginal delivery. The remaining 578 newborn infants (53.0\%) were born by caesarian section (CS), of which $73.2 \%$ as an emergency and $26.8 \%$ during planned CS. Of the 110 preterm infants, 22 ( $20.0 \%$ ) were born because of an induced anticipated delivery. Reasons for induced delivery were in nine situations retroplacental hematoma, in six cases haemorrhage with placenta pravia, in five cases pre-eclampsia, and in two situations eclampsia.

After delivery, the following diagnoses were mentioned in the patient records within the 1091 live born infants: 74 (6.8\%) asphyxia, 21 (1.9\%) congenital infection, and three (0.3\%) with malformations (1 hydrocephaly and 2 omphalocele).

Among the 1091 LB, 243 (22.3\%) showed a bad postnatal adaptation with an Apgar score at 1 minute $<$, of which 75 with an Apgar score 0-3. At 5 minutes, 9 infants had an Apgar score of 0-3 which corresponds according to the International Classification of Diseases to the diagnosis of severe asphyxia, and 99 infants (9.1\%) still had an Apgar score < 7 (13). By 10 minutes, 33 infants (3.0\%) remained with an Apgar score < 7

(Fig. 2). Table 2 summarizes the resuscitation manoeuvres and postnatal procedures needed in the early postnatal period. Of the 1091 LB, 304 (27.9\%) underwent some kind of resuscitation manoeuvres, 209 (19.2\%) of them needed bag and mask ventilation, and 82 (7.5\%) chest compression. A closer analysis showed that infants with a bad postnatal adaptation at 1 minute (Apgar score: 0-3) and/or at 5 minutes ( $<$ ) who benefitted from 'ventilatory support' had a 5 times higher chance to have a Apgar score $>7$ at ten minutes. Chest compression however did not show a beneficial effect (Table 3). According to the registry, nine infants died within the first postnatal hour despite resuscitation.

After this first stabilisation period, $192(17.6 \%)$ of the live born infants were transferred for ongoing neonatal care to the only neonatal clinic in Conakry, the Institute for nutrition and child health (INSE). All neonatal transports have been performed by private measures or public taxi without any medical or therapeutical support.

\section{Discussion}

This study demonstrates the highly difficult and worrisome situation of perinatal medicine in the Republic of Guinea. In the most developed referral clinic of obstetrics of the whole country, to which the most complicated pregnancies and deliveries are referred to, a stillbirth rate of $82 / 1000$ deliveries was measured. Almost $18 \%$ of all live born infants needed a higher degree of neonatal resuscitation, $8.2 / 1000$ LB died under resuscitation and $17.5 \%$ of all LB had to be transferred to a neonatal clinic for ongoing care.

\section{Stillbirths}

The high rate of stillbirths is particularly important to highlight, as this specific death rate is often neglected in hospital or national statistics, in which neonatal mortality and U5MR are reported in relation to LB. Data from the regional hospital of Kindia in Guinea showed a stillbirth rate of 47.7 per 1000 deliveries (14). According to the 'Every newborn action plan', developed by UNICEF and WHO, the stillbirth rate should decrease in each country to $\leq 12$ stillbirths/1000 total births by 2030 (4). Today, it is estimated that each year worldwide 2.6 million fetus are stillborn (2).

Page 3/11 
The few documented stillbirth rates in hospitals are usually higher than those estimated in the community (15). Nevertheless, the here reported stillbirth rate with 82 stillbirths /1000 total births is very high in comparison to other countries and hospital reports (15-17). A large metaanalysis about stillbirth reports from 50 countries showed a variety of causes. Data from low-income countries showed antepartal haemorrhage with $9.3 \%$, hypoxia with $11.6 \%$ and infection with $15.8 \%$ as the most important identified causes, whereas in the vast majority of situations (63.3\%) no clear causes have been described (18). Unfortunately, the data available in this study are too incomplete to identify the reasons for intrapartal stillbirths. It is also not possible to analyse, if improved intra-hospital care and/or an accelerated delivery could decrease the high intrapartum stillbirth rate, or if the problem is mainly due to a delayed arrival of the pregnant woman at the hospital. The latter reason is supported by the high rate of emergency caesarean section. A further indicator of insufficient late pregnancy control and delayed transfer to the hospital were the high rate of macerated stillbirths, the increased number of post mature infants and infants with a BW of $>4000 \mathrm{~g}$.

\section{Caesarean section rate}

The here described hospital CS rate with $>50 \%$ is very high. In contrast to high-income countries with high elective CS rates, in this study it is mainly due to a high number of emergency CS (19). There is hardly any other emergency treatment available for life threatening situations, either for mothers, nor for foetuses, then to terminate pregnancy by CS. No vaginal deliveries with instrumentation (forceps or vacuum extraction) were performed. The lack of therapeutical options other than termination of pregnancy is also decipherable in the context of preterm births. Whereas the overall prematurity rate is comparable to international values (20), the distribution according to preterm age groups and the causes for prematurity are quite different. In only $20 \%$ prematurity was medically indicated and provoked, in particular because of maternal reasons like retroplacentar haematoma or haemorrhage due to placenta praevia or in the context of pre- or eclampsia (21). The high rate of spontaneous preterm birth indicated that the pregnant women were referred to the hospital in situations where there was no time for preventable therapies like tocolysis or maternal antibiotic therapy in order to stabilize pregnancy to gain days or weeks. Such interventions to prevent prematurity would be even more important in countries like Guinea, in which very preterm and extremely preterm infants have almost no chances to survive.

\section{Birth weight anomalies}

Whereas the rate of LBW infants of $14 \%$ was similar to other African countries, macrosome infants were overrepresented with $10 \%$ compared to macrosome rates of 2-4\% (22-25). LBW as well as macrosomia are both independent risk factors for hospitalization in a neonatal unit (26); LBW infants due to immaturity, risk for hypothermia, hypoglycaemia, and respiratory distress; infants with BW $>4000 \mathrm{~g}$ due to increased risk for birth trauma, asphyxia and metabolic problems (25).

\section{Need for neonatal resuscitation}

The rate of infants needing resuscitation manoeuvres is very high, compared to other settings (27). This might indicate that improved examination of fetal intrapartum wellbeing and delivery management would be required. Almost $30 \%$ of all newborn infants needed any kind of resuscitation manoeuvres (tactile stimulation and/or airway aspiration), 2/10 of all infants needed additional bag and mask ventilation, and $7.5 \%$ were treated with chest compressions. In a similar setting in Tanzania, spontaneous respiration initiated in $84 \%$ of all LB infants, in $8 \%$ respiration commenced after tactile stimulation and/or suctioning and only in $8 \%$ bag and mask ventilation was necessary to start spontaneous respiration (28). Comparable data from three Norwegian hospitals are even lower with $17.5 \%$ for any resuscitation manoeuvres, $4.9 \%$ needing bag and mask ventilation and $0.1 \%$ chest compression (27). Chest compressions do not take part in the "Helping Babies Breathe" training and resuscitation program, which was taught at two occasions two years before the study period at this hospital (29). Our data do not support the use of chest compressions, as they didn't show a beneficial effect for improved postnatal adaptation. In contrary, respiratory support (airway cleaning and manual ventilation) hat a beneficial affect on improved Apgar score at 10 minutes after suppressed and delayed postnatal cardiopulmonary adaptation. It would be important to re-analyse neonatal resuscitation according to the proven beneficial resuscitation program “Helping Babies Breathe” (30).

Although Apgar score at 1 minute is a bad predictor for outcome, $88 \%$ of the 75 newborns with a very low 1-min-Apgar-score (0-3) remained instable and needed a transfer to the neonatal unit for further neonatal care. Apgar score at 5 minutes, however, was shown to be a strong predictor for death and cerebral palsy. Compared to children with 5 min Apgar scores of 7-10, those with a score of 0-3 had an almost 400 times increased risk for death and a 50-100x higher risk for cerebral palsy (31,32). Indeed, seven of the nine newborns with 5 min Apgar $0-3$ died within the first postnatal hour. Casey et al found a $13 x$ increased risk for neonatal death in preterm and $53 x$ increased risk in term infants, respectively, if 5-minute Apgar was 4-6 compared to 7-10 (33). This group of children (Apgar at 5 min 4-6) representing almost 9\% of the study population, fulfil also one of the clinical criteria for mild to moderate asphyxia. Unfortunately, no other clinical or laboratory criteria for the diagnosis of asphyxia were available in the study population. It would be very important to create a neonatal unit in close contact to the delivery room, in order to hospitalize, stabilize and better monitor by clinical and point of care laboratory measures all these newborn infants with adaptation problems for a longer time period, than just the first hour as it is use now.

\section{Neonatal transport}

Page $4 / 11$ 
Lacking a neonatal unit at the same location, $17.6 \%$ of all live born infants had to be transferred postnatally. Indication for referral were mainly prematurity (85\%), respiratory distress (62\%) and in $11 \%$ neonatal infection. The high rate of respiratory distress corresponds to data presented by McEvoy et al in Western Switzerland (34). However, whereas in Switzerland respiratory support is guaranteed during transportation in a fully equipped and medicalized ambulance, professional neonatal transport does not exist in Conakry. The emergency transports of suffering infants were all performed by private vehicles or public taxis, without medical or paramedical assistance and without any kind of respiratory support. This might lead to a serious deterioration of the respiratory status, with some infants arriving dead at their destination. A study performed in a similar neonatal referral context from Dakar described mortality during transport in $2.3 \%$. Additional $4.6 \%$ of transferred newborns presented with cardiorespiratory arrest just at arrival (35). Such data strongly suggest the creation of a medicalized neonatal transport system for the Conakry area.

\section{Perinatal morbidity and mortality}

Despite resuscitation manoeuvres, nine of the 1091 live born infants did not survive the first minutes of postnatal life, representing a resuscitation mortality of 8.2/1000 LB. Unfortunately, no data are available about the short and long term outcome of the transferred newborns. However, in a retrospective study of the second university maternity existing in Conakry (Donka National Hospital), mortality rate of the transferred newborn infants to the same neonatal intensive care unit, was shown to be $41.7 \%$ (36). In a separate evaluation performed at the INSE during the same year as the presented study, a total mortality rate of $39.9 \%$ of all admitted newborn infants was measured. For the infants referred from the Ignace Deen University Hospital, a mortality rate within the first seven days after hospitalisation at the INSE was at 33\% (unpublished data). Taken all this data together, the perinatal mortality accounts as follows: of the 1189 deliveries, there are 98 stillbirths and nine infants died during resuscitation. With an early neonatal mortality (within the seven first postnatal days) rate of $33 \%$, of the 192 transferred infants additional 64 fatal outcomes would have to be added. Altogether, the number of stillbirths, of the direct postnatally deceased infants and of these neonatal deaths within the first week of life, the total perinatal death rate rises to $143.8 / 1000$ total births, or one dead infant in seven births.

\section{Limitations of this study}

There were quite a number of limitations added to this study. Being limited to the data of this maternity hospital, information about the outcome of the newborn infants is lacking. The calculated mortality rates are not representative for the whole population of Guinea. However, the results of this study were meant to give some indicators for policy makers and health care providers how the regional perinatal network collaboration could be improved in order to reduce this very high perinatal mortality rate.

\section{Conclusions}

Perinatal mortality in the largest clinic of obstetrics in Guinea is very high with a fatal outcome in one out of seven deliveries. Potential factors involved were delayed referral, limited resources and therapeutical options for emergencies and a non-existing neonatal unit for newborns in need of postnatal intensive care. As emergency measures in this clinic, an efficient triage system for transferred women in labour should be established in order to avoid intrahospital delays. Furthermore, neonatal resuscitation needs to get standardized according to the HBB-program, a neonatal stabilization unit has to be created in proximity to the delivery room and the obstetric surgical theatre must be equipped with emergency respiratory support and staffed by trained personal for neonatal emergency care. The caseload of the Conakry area is big enough to install a neonatal transport system with ambulances supplied with oxygen and respiratory support in order not to interrupt life-saving neonatal care during transportation.

\section{List Of Abbreviations}

BW Birth weight

CS Caesarean section

GA Gestational age

HBB Helping Babies Breathe Program

INSE Institut de Nutrition et de Santé de l'Enfant; Institute for nutrition and child health

LBW Low birth weight $(<2500 \mathrm{~g})$

LMIC Low and middle-income countries

MICS Multiple indicator cluster survey 
MDG 4 Millenium developmental goal number 4

U5MR Under-5-mortality rate

UNICEF United Nations Children's Fund

WHO World health organization

\section{Declarations}

\section{Ethics approval}

The study was approved by the bioethical Committee of the National University Hospital Ignace Deen in Conakry. The parents were informed about the goal of the study, and their right for non-acceptance. The individual data was used for scientific purposes only, according to the legal regulations on privacy applicable in Guinea. No written informed consent was required.

\section{Availability of data}

The datasets used and analysed during the current study are available from the corresponding author on reasonable request.

\section{Competing interests}

The authors declare that they have no competing interests.

\section{Funding}

There was no funding for this study.

\section{Author's contribution}

$A D$ initiated the study, wrote the protocol, analysed data and performed tables. Patient recruitment and data acquisition were performed by IKD and MCD. MRK, DD and AD wrote the manuscript. DD made statistical analyses. ISD and TS gave scientific advises, helped interpreting the data and revising the manuscript. All authors read and approved the final manuscript.

\section{Acknowledgements}

Not applicable

\section{References}

1. UN Inter-agency Group for Child Mortality Estimation You DHL, Chen Y, Wardlaw T, Newby H. and UN Inter-agency Group for Child Mortality Estimation. Levels and trends in Child mortality. https://www.unicef.org/media/files/Levels_and_Trends_in_Child_Mortality_2014.pdf: UNICEF; 2014.

2. Lawn JE, Blencowe H, Waiswa P, Amouzou A, Mathers C, Hogan D, et al. Stillbirths: rates, risk factors, and acceleration towards 2030. Lancet. 2016;387(10018):587-603.

3. Zupan J. Perinatal mortality in developing countries. N Engl J Med. 2005;352(20):2047-8.

4. WHO. Every newborn: an action plan to end preventable deaths 2014. Available from: https://apps.who.int/iris/bitstream/handle/10665/127938/9789241507448_eng.pdf;jsessionid=03F48D982F67934FC693E1F53E5C8232? sequence $=1$.

5. You D, Hug L, Ejdemyr S, Idele P, Hogan D, Mathers C, et al. Global, regional, and national levels and trends in under-5 mortality between 1990 and 2015, with scenario-based projections to 2030: a systematic analysis by the UN Inter-agency Group for Child Mortality Estimation. Lancet. 2015;386(10010):2275-86.

6. WHO. The World Health Report 2005 - make every mother and child count. WHO; 2005.

7. WHO. Neonatal and perinatal mortality: country, regional and global estimates Organization WH, editor2006.

8. Cousens S, Blencowe H, Stanton C, Chou D, Ahmed S, Steinhardt L, et al. National, regional, and worldwide estimates of stillbirth rates in 2009 with trends since 1995: a systematic analysis. Lancet. 2011;377(9774):1319-30.

9. Gomes da Silva Rego MBRVC, Vieira do Bonfim C. Perinatal deaths preventable by intervention of the Unified Health System of Brazil. Revista Gaucha de Enfermagem. 2018;39(e2017-0084). 
10. Kc A, Wrammert J, Clark RB, Ewald U, Vitrakoti R, Chaudhary P, et al. Reducing Perinatal Mortality in Nepal Using Helping Babies Breathe. Pediatrics. 2016;137(6).

11. Ntambue A, Malonga F, Dramaix-Wilmet M, Donnen P. [Perinatal mortality: extent and causes in Lubumbashi, Democratic Republic of Congo]. Rev Epidemiol Sante Publique. 2013;61(6):519-29.

12. Statistique INdl. Enquête Démographique et de Santé en Guinée 2018. UNICEF; 2018.

13. WHO. International Statistical Classification of Diseases for Mortality and Morbidity Statistics, 11th Revision 2019. Available from: https://icd.who.int/icd11 refguide/en/index.html.

14. Diallo FBBI, Diallo BS, Diallo A, Baldé O, Conté I, Beavogui A, Diallo B. Mortinatalité: aspects sociodémographiques à l’hôpital régional de Kindia en Guinée. 2015;7:187-91.

15. Berhan Y, Berhan A. Perinatal mortality trends in Ethiopia. Ethiop J Health Sci. 2014;24 Suppl:29-40.

16. Okonofua FE, Ntoimo LFC, Ogu R, Galadanci H, Mohammed G, Adetoye D, et al. Prevalence and determinants of stillbirth in Nigerian referral hospitals: a multicentre study. BMC Pregnancy Childbirth. 2019;19(1):533.

17. Nonterah EA, Agorinya IA, Kanmiki EW, Kagura J, Tamimu M, Ayamba EY, et al. Trends and risk factors associated with stillbirths: A case study of the Navrongo War Memorial Hospital in Northern Ghana. PLoS One. 2020;15(2):e0229013.

18. Reinebrant HE, Leisher SH, Coory M, Henry S, Wojcieszek AM, Gardener G, et al. Making stillbirths visible: a systematic review of globally reported causes of stillbirth. BJOG. 2018;125(2):212-24.

19. Betran AP, Ye J, Moller AB, Zhang J, Gulmezoglu AM, Torloni MR. The Increasing Trend in Caesarean Section Rates: Global, Regional and National Estimates: 1990-2014. PLoS One. 2016;11(2):e0148343.

20. Blencowe H, Cousens S, Oestergaard MZ, Chou D, Moller AB, Narwal R, et al. National, regional, and worldwide estimates of preterm birth rates in the year 2010 with time trends since 1990 for selected countries: a systematic analysis and implications. Lancet.

2012;379(9832):2162-72.

21. Ananth CV, Vintzileos AM. Epidemiology of preterm birth and its clinical subtypes. J Matern Fetal Neonatal Med. $2006 ; 19(12): 773-82$.

22. Baye Mulu G, Gebremichael B, Wondwossen Desta K, Adimasu Kebede M, Asmare Aynalem Y, Bimirew Getahun M. Determinants of Low Birth Weight Among Newborns Delivered in Public Hospitals in Addis Ababa, Ethiopia: Case-Control Study. Pediatric Health Med Ther. 2020;11:119-26.

23. He Z, Bishwajit G, Yaya S, Cheng Z, Zou D, Zhou Y. Prevalence of low birth weight and its association with maternal body weight status in selected countries in Africa: a cross-sectional study. BMJ Open. 2018;8(8):e020410.

24. Essel JK, Opai-Tetteh ET. Macrosomia-maternal and fetal risk factors. S Afr Med J. 1995;85(1):43-6.

25. Said AS, Manji KP. Risk factors and outcomes of fetal macrosomia in a tertiary centre in Tanzania: a case-control study. BMC Pregnancy Childbirth. 2016;16:243.

26. Andegiorgish AK, Andemariam M, Temesghen S, Ogbai L, Ogbe Z, Zeng L. Neonatal mortality and associated factors in the specialized neonatal care unit Asmara, Eritrea. BMC Public Health. 2020;20(1):10.

27. Skare C, Kramer-Johansen J, Steen T, Odegaard S, Niles DE, Nakstad B, et al. Incidence of Newborn Stabilization and Resuscitation Measures and Guideline Compliance during the First Minutes of Life in Norway. Neonatology. 2015;108(2):100-7.

28. Ersdal HL, Mduma E, Svensen E, Perlman JM. Early initiation of basic resuscitation interventions including face mask ventilation may reduce birth asphyxia related mortality in low-income countries: a prospective descriptive observational study. Resuscitation. 2012;83(7):869-73.

29. Kamath-Rayne BD, Thukral A, Visick MK, Schoen E, Amick E, Deorari A, et al. Helping Babies Breathe, Second Edition: A Model for Strengthening Educational Programs to Increase Global Newborn Survival. Glob Health Sci Pract. 2018;6(3):538-51.

30. Versantvoort JMD, Kleinhout MY, Ockhuijsen HDL, Bloemenkamp K, de Vries WB, van den Hoogen A. Helping Babies Breathe and its effects on intrapartum-related stillbirths and neonatal mortality in low-resource settings: a systematic review. Arch Dis Child. 2020;105(2):127-33.

31. Moster D, Lie RT, Irgens LM, Bjerkedal T, Markestad T. The association of Apgar score with subsequent death and cerebral palsy: A population-based study in term infants. J Pediatr. 2001;138(6):798-803.

32. Lie KK, Groholt EK, Eskild A. Association of cerebral palsy with Apgar score in low and normal birthweight infants: population based cohort study. BMJ. 2010;341:c4990.

33. Casey BM, Mclntire DD, Leveno KJ. The continuing value of the Apgar score for the assessment of newborn infants. N Engl J Med. 2001;344(7):467-71.

34. McEvoy CG, Descloux E, Barazzoni MS, Diaw CS, Tolsa JF, Roth-Kleiner M. Evaluation of Neonatal Transport in Western Switzerland: A Model of Perinatal Regionalization. Clin Med Insights Pediatr. 2017;11:1179556517709021.

35. Mosca F, Colnaghi M. [Delivery room intensive care unit]. Minerva Pediatr. 2010;62(3 Suppl 1):15-6.

Page $7 / 11$ 
36. Diallo ISDS, Bah EM, Djuikouo TA, Diallo TS, Conte N, Niane H, Cisse M, Keita N, Sy T. Risk factors for mortality of newborns referred from Donka maternity clinic to the Institute of child nutrition and health (INSE) over 10 years of activity. Annales de la SOGGO. 2019;14(32):1824.

\section{Tables}

Table 1:

Epidemiological and clinical data of infants born during the study period:

\begin{tabular}{|c|c|c|}
\hline Clinical data at birth & $\mathbf{n}$ & $\%$ \\
\hline \multicolumn{3}{|l|}{ Vitality $(\mathrm{n}=1189)$} \\
\hline Live births & 1091 & 91.8 \\
\hline Stillbirths & 98 & 8.2 \\
\hline \multicolumn{3}{|l|}{ Type of stillbirths $(n=98)$} \\
\hline Recent stillbirths & 41 & 41.8 \\
\hline Stillbirths with signs of maceration & 57 & 58.2 \\
\hline \multicolumn{3}{|l|}{ Maturity of newborn infants $(n=1189)$} \\
\hline Mature & 980 & 82.4 \\
\hline Prematuré & 110 & 9.3 \\
\hline Post term & 99 & 8.3 \\
\hline \multicolumn{3}{|l|}{ Birth weight in grams ( $\mathrm{n}=1189$ ) } \\
\hline$<2500$ & 167 & 14.0 \\
\hline $2500-3999$ & 896 & 75.4 \\
\hline$\geq 4000$ & 126 & 10.6 \\
\hline \multicolumn{3}{|c|}{$\begin{array}{l}\text { Mean birth weight: } 2938 g \text { (Standard deviation : } 736 g \text { ); } \\
\text { Range: } 965 \mathrm{~g}-5200 \mathrm{~g}\end{array}$} \\
\hline \multicolumn{3}{|l|}{ Head circumference $(n=1189)$} \\
\hline \multicolumn{3}{|l|}{ Mean: $33 \mathrm{~cm}(\mathrm{SD}: 3 \mathrm{~cm})$} \\
\hline \multicolumn{3}{|l|}{ Range: $27-36 \mathrm{~cm}$} \\
\hline \multicolumn{3}{|l|}{ Birth length ( $n=1189)$} \\
\hline \multicolumn{3}{|l|}{ Mean: $49 \mathrm{~cm}(\mathrm{SD}: 4 \mathrm{~cm})$} \\
\hline \multicolumn{3}{|l|}{ Range: $44-56 \mathrm{~cm}$} \\
\hline \multicolumn{3}{|c|}{ Postnatal diagnoses of live born newborn infants $(n=1091)$} \\
\hline Asphyxia & 74 & 6.8 \\
\hline Infection & 21 & 1.9 \\
\hline Malformation & 3 & 0.3 \\
\hline \multicolumn{3}{|l|}{ Type of malformation $(n=3)$} \\
\hline Hydrocephalus & 2 & 66.7 \\
\hline Omphalocele & 1 & 33.3 \\
\hline
\end{tabular}

Table 2:

Postnatal adaptation and immediate outcome of the live births 


\begin{tabular}{lrr}
\hline Adaptation and immediate outcoome & $\mathrm{n}$ & $\%$ \\
\hline Any sort of resuscitation manoeuvres $(\mathrm{n}=1091)$ & & \\
& 304 & 27.9 \\
Resuscitation manoeuvres $(\mathrm{n}=\mathbf{3 0 4})$ & & \\
Tactile simulation & 289 & 95.1 \\
Upper airway aspiration & 212 & 69.7 \\
Bag and mask ventilation & 209 & 68.8 \\
Chest compressions & 82 & 27.9 \\
& & \\
Immediate death despite resuscitation $(\mathrm{n}=304)$ & 9 & 3.0 \\
& & \\
Transfer to neonatal unit (n=1091) & 192 & 17.6 \\
& & \\
Transfer indications ( $=192)$ & & \\
(More than 1 indication possible) & 164 & 85.4 \\
Prematurity & 119 & 62.0 \\
Respiratory distress & 2 & 1.0 \\
Malformation & 21 & 10.9 \\
Neonatal infection &
\end{tabular}

Table 3:

Association between primary resuscitation measures after birth and Apgar-score at 10 minutes $>7$, according to Apgar-score at 1 minutes $<4$ and newborns with poor prognosis defined by Apgar-score $<4$ at 1 minute and $<7$ at 5 minutes.

\begin{tabular}{|c|c|c|}
\hline \multirow{2}{*}{ Apgar at 1 minutes $<4(N=102)$} & Crude OR [95\%CI] & $\mathrm{aOR}[95 \% \mathrm{CI}]$ \\
\hline & & \\
\hline Tactile stimulation & - & - \\
\hline Ventilatory support & $3.65[1.4-9.5]$ & $5.0 \quad[1.8-14.6]$ \\
\hline Cardiac massage & 0.13 [0.02-1.17] & $0.3[0.1-0.9]$ \\
\hline \multicolumn{3}{|l|}{ Poor prognosis $(N=68)$} \\
\hline \multicolumn{3}{|l|}{ (Apgar at 1 minute $<4$ and Apgar at 5 minutes $<7$ ) } \\
\hline Tactile stimulation & - & $-\quad-$ \\
\hline Ventilatory support & $6.4 \quad[1.7-38.5]$ & $9.4 \quad[1.8-47.2]$ \\
\hline Cardiac massage & $0.3[0.13-1.7]$ & 0.4 [0.1-1.6] \\
\hline
\end{tabular}

Legend: CI: Confidence interval ; OR: Odds ratio ; aOR: adjusted Odds Ratio.

\section{Figures}




\section{Distribution of preterm infants$$
(n=110)
$$

70

60

50

40

30

24

20

10

0

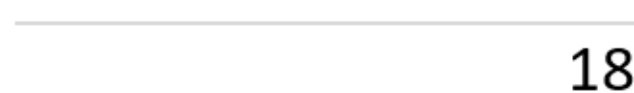
Extremely preterm
Very preterm
Moderately preterm
Late preterm
( $<28$ weeks)
(28 - 316/7 weeks)
(32 - 33 6/7 weeks)
(34-36 6/7 weeks)

\section{Figure 1}

Distribution of preterm infants according to the different degrees of prematurity

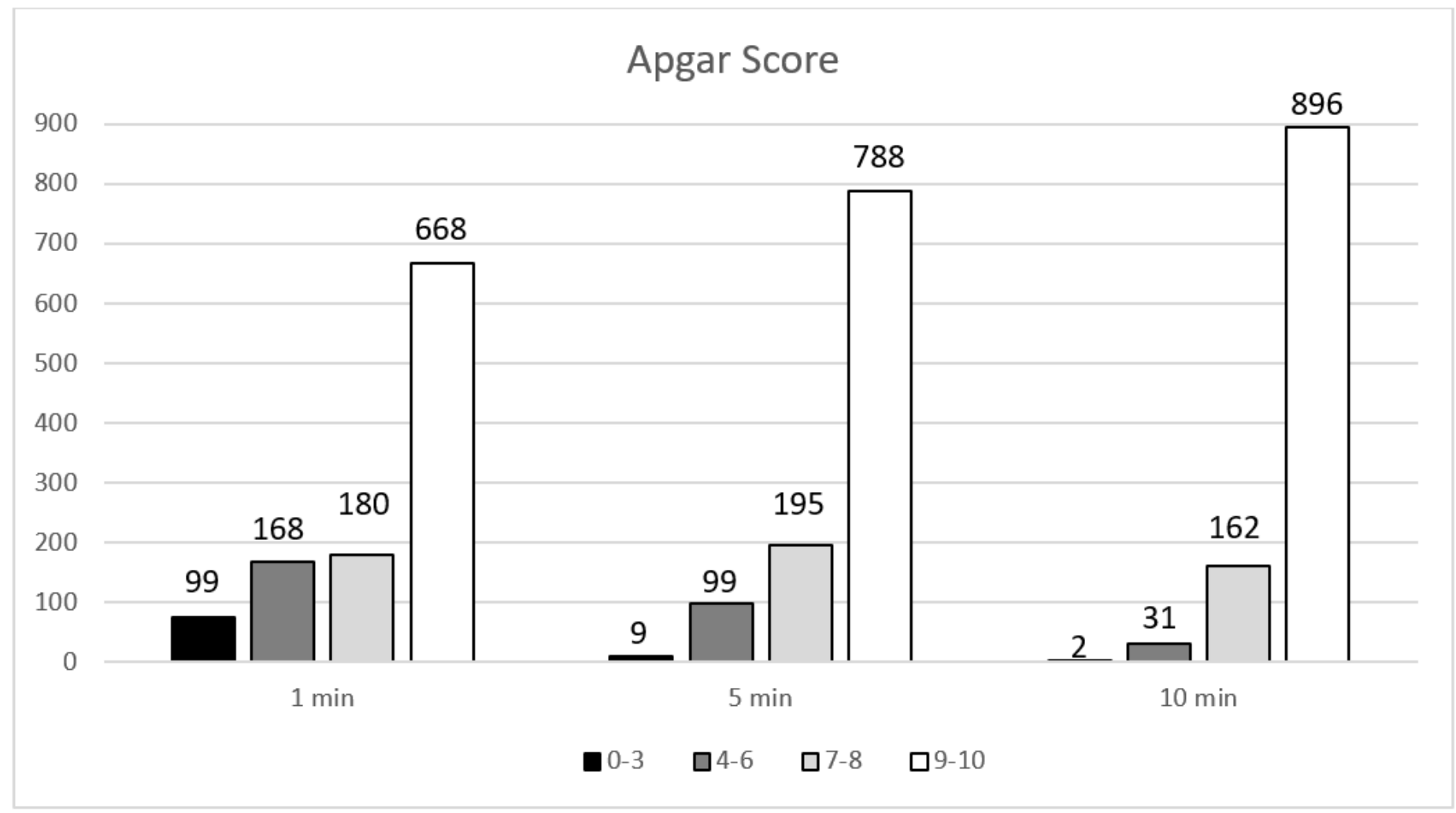

Figure 2 
Number of patients within different Apgar score groups at 1, 5, and 10 minutes of postnatal life.

Page 11/11 